\title{
Heidegger e o mito da conspiração judaica mundial
}

\section{Peter Trawny}

Tradução de Soraya Guimarães Hoepfner

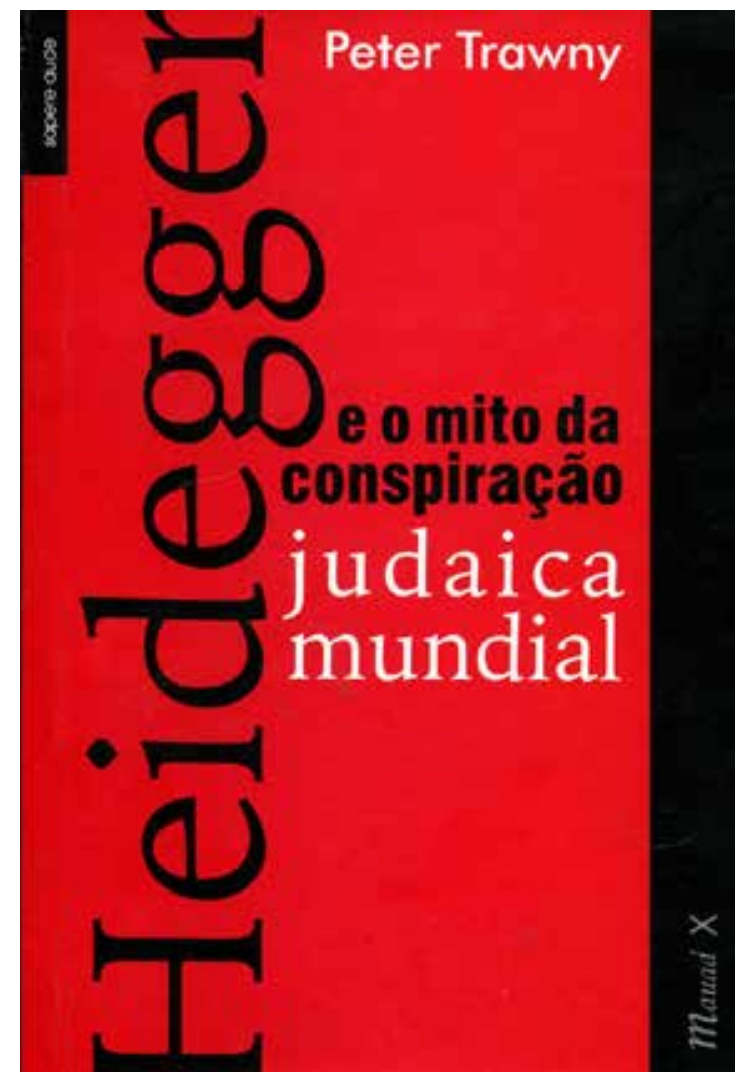

\section{por Dra. Soraya Guimarães Hoepfner}

soraya.hoepfner@gmail.com

TRAWNY, Peter. Heidegger e o mito da conspiração judaica mundial. Trad. Soraya Guimarães Hoepfner. Rio de Janeiro: Mauad, 2015. 
Desde o lançamento, em meados de fevereiro de 2014, do primeiro dos nove volumes dos Cadernos Negros, compêndio de anotações filosóficas de Martin Heidegger, a comunidade filosófica mundial viu-se novamente confrontada direta e, desta vez definitivamente, com a controversa questão sobre a posição política do filósofo alemão nos anos que antecederam, que perduraram e até mesmo nos anos pós II Guerra Mundial. Especialmente nos três primeiros volumes já publicados, 94 a 96 (HEIDEGGER, 2014; 2015), que trazem anotações que datam de 1931 a 1941, estão contidas diversas passagens filosóficas relacionadas ao conflito bélico mundial, especialmente à visão de Heidegger sobre o povo alemão, além de algumas passagens sobre o povo judeu.

Antes mesmo ou sem que seja preciso ler o primeiro volume, a mais imediata e óbvia reação, comum tanto a detratores como a defensores do filósofo, seria a constatação de que o fato em si nada teria de novo; desde sempre existiu e acompanhou a obra de Heidegger, como uma pesada sombra, por todas essas décadas o fato de o filósofo ter se envolvido com o nazismo partidário na sua época. Deste modo, sua simpatia e adesão ao nacional-socialismo, pontual ou não, sempre esteve em pauta, com maior ou menor destaque, seja como questionamento central e motivador de obras inteiras (FARÍAS, 1988; FAYE, 2014), seja indiretamente, como apelo comercial ou como anedota nas rodas de conversa e encontros filosóficos mundo afora. Heidegger, nazista, antissemita não seria novidade. Seria de se perguntar, então, independentemente da publicação da nova série de escritos, o que mais poderia ainda render esse tema desgastado que, sobretudo, pouco ou nada tem de filosófico. No entanto, há um elemento novo, sutil e ao mesmo tempo com força suficiente para ser inquietante, aquele que justamente o livro introdutório de Peter Trawny, ele mesmo editor dos Cadernos Negros, traz à tona. Trata-se, com base em passagens explícitas de menção à questão judaica que se encontram especialmente no terceiro volume dos Cadernos, de se perguntar em que medida e em qual extensão o pensamento filosófico de Heidegger não teria sofrido, a partir de então, uma "contaminação" (p. 18) por uma ideologia do antissemitismo. Para esta pergunta central o livro não se encarrega de apresentar uma resposta decisiva e definitiva, mas tão somente de formulá-la através de uma cuidadosa recuperação histórica e sobretudo filosófica dos elementos conceituais em torno dessa dúvida.

Agora, diante da óbvia pertinência da hipótese - qual seja, é possível que determinados conceitos e formulações filosóficas ensaiados ou embrionados nas imediações temporais da II Guerra Mundial tenham tido como ponto de partida um viés antissemita -, é praticamente impossível mantermos simplesmente qualquer uma das posturas simplistas de negação, relativização ou su- 
mária condenação no domínio do questionar filosófico. Ignorar e abstrair do questionamento, seja em defesa de uma pureza institucional ou para insistir na presunção acusatória que precocemente encerra a questão, tornam-se saídas fáceis para o problema. Mais ainda, aqueles realmente interessados nos estudos heideggerianos, se optarem pela fuga da realidade, deixam o caminho livre para a forte campanha difamatória vista nos últimos meses, que curiosamente surge devotada à condenação peremptória da filosofia heideggeriana como principal pauta de produção científica; por si só, um contrassenso.

Deste modo, o livro de Trawny, não obstante as diversas margens para interpretação da sua interpretação, coloca-se no epicentro do problema filosófico, legítimo, em questão e ao mesmo tempo apresenta-se como meio termo entre tais polarizações extremas. Ao analisar como Heidegger desenvolve determinados conceitos nos bastidores do seu pensamento filosófico, no momento histórico exato em que os alemães acreditavam piamente estar sob o ataque conspiratório do judaísmo em escala mundial, Trawny traz para primeiro plano no mínimo duas importantes perguntas, dentre tantas outras que uma leitura produtiva do seu livro possam vir a sugerir ao leitor: a primeira, central e universal, é acerca dos limites entre filosofia e ideologia, de que maneira é possível delimitar a extensão na qual preconceitos podem se distinguir de conceitos, sobretudo de conceitos filosóficos. A segunda, colateral e aplicada, de que maneira daqui por diante podemos ler tais conceitos filosóficos heideggerianos surgidos ou consolidados nessa época, como também seus desdobramentos, ante a ressonância dessa ideologia antissemita. As respostas não estão no livro, nem mesmo as perguntas se deixam elaborar facilmente, contudo é ainda mais difícil descaracterizá-las como irrelevantes, pois trata-se agora de ensaiar, às vésperas dos 30 anos de sua morte, uma necessária e inevitável primeira hermenêutica dos polêmicos escritos político-filosóficos de Heidegger, uma tarefa que em sua essência revela-se como a questão geral da relação entre história do mundo e filosofia. Desta vez, contudo, parece ser possível ter elementos para que tal tarefa não se resuma a comentar factoides, fazer especulações ou dados historiográficos.

No livro em questão, que surge publicado no Brasil na versão de sua terceira edição original, o autor trata preliminarmente de compor um cenário introdutório para a primeira e mais fácil pergunta, aquela que trata factualmente da atitude política de Heidegger e sua adesão ao Nacional-socialismo, enfatizando sobretudo o amplo espectro de personagens - em sua maioria, filósofos - em torno de si. Ele também apresenta um preâmbulo, uma espécie de bastidores dos bastidores da feitura dos Cadernos Negros, no qual o leitor pode melhor compreender o indispensável contexto, se quisermos, operacional das obras. 
Ademais, o autor esclarece de modo simples e direto determinadas acepções, entre elas, o que é propriamente antissemitismo, uma compreensão-chave, curiosamente por vezes negligenciada como elemento fundamental para se aproximar adequadamente, tanto das passagens polêmicas, quanto das alegações e sobretudo acusações.

O grande risco assumido por Trawny surge, no entanto, quando o autor se aproxima do conceito de "historicidade de Ser", para ele uma "narrativa" (p. 23) que funda-se duplamente numa tentativa visionária de restauração da pertença direta do pensamento alemão (nomeadamente, o de Heidegger) com o pensamento originário grego, à guisa de operar um "segundo começo" ( $\mathrm{p}$. 32) e, ao mesmo tempo, numa oposição enfática aos valores da modernidade, responsáveis na sua visão por operar o desenraizamento e distanciamento do homem de seu modo de ser mais essencial. Como agravante, esse modo de ser, que na visão de Heidegger encarrega-se de realizar uma "desracialização dos povos" (p. 38), aparece emblematizado na figura do judeu, agora uma espécie de antagonista nessa "narrativa".

Como fica óbvio, o problema em si não está simplesmente no caráter antimodernista do discurso heideggeriano em favor de uma estada originária e ligada ao solo e às raízes (no caso, solo e raízes do povo alemão), mas na explícita - como aponta Trawny - associação desse espírito moderno desenraizado à figura do povo judeu, por conseguinte, do Judaísmo. Esse antagonismo, que o autor pontua como forte traço do "maniqueísmo onto-historial" (p. 28) torna-se então o calcanhar de Aquiles de todos os conceitos adjetivados como "onto-historiais" e, não somente isso, abre um precedente comprometedor para todo o discurso heideggeriano acerca da modernidade, pilar essencial sobre o qual se funda, por exemplo, a tão chamada 'questão da técnica' em Heidegger, até então, quando não louvada e tomada como fonte de inspiração para gerações de filósofos e pesquisadores nas mais diversas áreas das Humanidades, criticada apenas como romântica e nostálgica (IHDE, 2010).

Quanto às declarações tidas como antissemitas per se, essa aparecem reproduzidas ipsis litteris e minunciosamente comentadas no livro. Trata-se, até o presente, de nada mais do que três passagens ${ }^{1}$ em que Heidegger explicitamente se refere negativamente ao Judaísmo em seu discurso filosófico, ou seja,

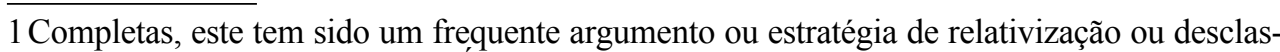
sificação da validade da questão. É de se perguntar porém, considerando a importância e papel do filósofo para o pensamento contemporâneo e, ainda, o fato de o teor dos Cadernos Negros, preparados cuidadosamente pelo próprio Heidegger, se acima de tudo uma questão de "quantidade" é cabível, ou seja, se há uma medida para injúria racial, quanto seria o bastante? 
e aí está o grande problema, no âmbito da verdade filosófica. Como bem argumenta o autor, é impossível dissociar o contexto das declarações (bastidores da II Guerra Mundial) do teor negativo em si, de modo que relativizar e atribuir a essas passagens apenas o rótulo de 'uma crítica ao judaísmo' (VIETTA, 2015) no momento em que milhões de judeus encontravam os campos de concentração como destino final, poderia se dizer, é uma visão parcial ou quiçá ingênua. É com base no teor dessas declarações, surgidas no contexto de elucubrações filosóficas, que o autor, por conseguinte, caracteriza o que ele denomina como “antissemitismo historial", uma espécie de fundamento filosófico à base do antissemitismo comum da época.

Esse componente está ilustrado em passagens como: "A pergunta pelo papel do Judaísmo mundial não é racial, mas sim uma pergunta metafísica pelo modo de ser do tipo de ser-homem, que completamente desarraigado pode assumir o desenraizamento de todos os entes de Ser, enquanto 'tarefa' histórica mundial" (p. 39). Imaginar tais formulações como 'não-filosóficas' ou opinião pessoal, em se tratando de declarações do filósofo certamente mais influente para as gerações posteriores da chamada filosofia continental, seria, portanto, no mínimo, negligenciar a necessidade de uma análise mais demorada sobre a questão.

Diante da ideia de que Heidegger teria elaborado uma perspectiva filosófica através da qual se fundamenta (e se justifica) um determinado caráter pejorativo, aparentemente próprio, se não exclusivo, dos judeus, Trawny acena com uma alternativa, a de que essa postura, enquanto que filosófica, distingue-se, no entanto, do antissemitismo banal e comum. Por essa mesma via, o autor também observa uma diferença clara entre uma postura simpática de Heidegger à ideia do nacional-socialismo: ela não se estenderia ao "Nacional-socialismo vulgar" (p. 33), ou seja, aquele de fato, o "real existente" (p.131). Trawny sugere pressupor que a linha de pensamento de Heidegger se guia por uma dissociação entre sujeitos universais e entidades ônticas, ao mesmo tempo em que torna evidente a fragilidade, senão o absurdo de tal estratégia filosófica; insustentável diante do momento de mundo. Aqueles eram tempos de guerra, com um peso e pressão concretos sobre a realidade cotidiana de cada um, sobretudo dos pensadores de seu tempo. Tanto, que até mesmo um jargão e um tom típico da esfera pública naquele momento podem ser identificados em referências cruzadas pelo autor, como é o caso da similaridade de discurso com o panfletário Protocolos dos Sábios de Sião (p. 46), na demonstração concreta de um elo entre os acontecimentos históricos que levaram ao antagonismo dos judeus pelos alemães, e precisamente o 'eventoapropriador', o qual Heidegger elaborou esperançosamente como ligado à missão derradeira de seu povo, o povo alemão. 
Assim, sob o viés do "ontohistorial", as ideias de Heidegger sobre raça, povo, solo são contextualizadas no seio de sua declarada oposição a um determinado modo de ser, algo que obviamente está para além de um simples 'estilo de vida', e que é tido como ameaça porque não somente simboliza, mas sobretudo promove, nas palavras do próprio Heidegger, a "desracialização total dos povos" (p. 38). A superposição desse modo de ser desenraizado com o povo judeu é explícita. Tardiamente, como se sabe, esse modo de ser em geral passa a caracterizar o homem moderno diante da tecnologia. A permanência posterior de determinados conceitos - o que todavia não sugere sua imutabilidade -, tais como "maquinação" (p. 27), que surge do campo semântico dessa época, é inegável. O Embora a ideia de um 'antissemitismo onto-historial' seja inquietante e provavelmente ainda careça, como já mencionado, de uma análise mais demorada e profunda, ao formulá-la, Trawny está longe de tender a uma condenação sumária, postura pela qual o autor sofre a maioria dos ataques advindos da atitude típica de 'mate o mensageiro'. O debate tem pouco mais de um ano, ânimos ainda não estão arrefecidos, e a discussão, em todos os níveis e para todos os atores centrais dela encarregados, também já evoluiu desde a publicação desse livro seminal, provocando uma série de respostas, como a recente de Jean-Luc Nancy (2015), intitulada Banalidade de Heidegger, a ser lançada em breve na França, ou até mesmo a curiosa revisão intitulada $\mathrm{O}$ caso Trawny (COHEN-HALIMY, 2015). que de fato isso representa para os estudos heideggerianos é uma das perguntas que o livro inaugura. Afinal, não esqueçamos que a filosofia fundamental de Heidegger sobre a modernidade em questões como a técnica e a história estão à base de praticamente todas as vertentes atuais, até mesmo quando surgem exatamente para negá-la.

Seguindo adiante na composição de um recorte histórico e filosófico que sucintamente reúne elementos para uma continuada discussão, o autor também dedica especial atenção a duas figuras importantes na vida de Heidegger, ambas de origem judaica, e suas conturbadas relações com o filósofo, que frequentemente surgem mencionadas no contexto: Husserl, seu orientador e figura 'paterna' e Arendt, sua aluna e também, por um breve período, sua amante. Em ambas, o autor apresenta uma narrativa concisa e imparcial dos fatos que em muito corrobora com uma aproximação da figura humana de Heidegger que se pretenda menos novelesca. Ambas são também ilustrações necessárias, pois trata-se de elaborar elementos para também compreender o homemfilósofo em seus dilemas respectivamente profissionais e pessoais.

A terceira edição traz adendos desenvolvidos como reflexo às primeiras repercussões do livro na comunidade filosófica. Entre eles, a seção "Exterminação e autoexterminação", desenvolvida na sequência do colóquio organizado 
em outubro de 2014 na sede do Instituto Martin Heidegger sobre o tema. O capítulo traz um componente abordado pela filósofa Marcia Schuback (2015) durante o evento, onde Trawny introduz de maneira mais direta o elo entre os antagonismos exacerbados no contexto da guerra, ao qual Heidegger confere um status "historial de ser" e o caráter de "consumação" (p. 102) extrema da técnica que finda por operar uma espécie de consumação de si mesma, o que o autor vê em Heidegger como a atribuição de uma função de "redução apocalíptica" da História. $\mathrm{O}$ autor elenca os vários tons que pertencem a esse campo semântico apocalíptico da época, de maneira a compor o cenário do pensamento filosófico que até então mostrava-se somente pelos escritos tidos como esotéricos de volumes como Meditação (HEIDEGGER, 2010) ou Contribuições à filosofia (HEIDEGGER, 2015).

O capítulo seguinte "Após a Shoah", encarrega-se de nos colocar diante da questão, com o fim da guerra, o que de fato extingue-se e o que permanece não só na postura, conhecidamente a do silêncio, mas sobretudo no pensamento de Heidegger? A remontagem dos principais pontos da repercussão do posicionamento político de Heidegger ante a comunidade filosófica é feita, notadamente, atendo-se ao contexto particular daquele momento, num esforço do autor, o que aliás se encontra em todo o livro, de tentar evidenciar o anacronismo insuperável com o qual nos confrontamos ao refletir sobre os acontecimentos no hoje. Esta seção é o preâmbulo para uma "Tentativa de resposta", na qual o autor apesar do título não responde, mas talvez contribua para algo mais importante, articular uma saída de reflexão na qual é possível aceitar e compreender como um evento de proporções aterrorizantes (no caso concreto, a II Guerra Mundial) se insere na filosofia (a de Heidegger), evidenciando assim a exigência que todo evento faz para si, de ser pensado.

Recebido em: 18/11/2015 Aprovado em: 15/02/2016

COHEN, F.,COHEN-HALIMY, M. Les cas Trawny. $\grave{A}$ propôs des Cahiers Noirs de Heidegger. Paris: Sens \& Tonka, 2015.

FARÍAS, V. Heidegger e o nazismo. Rio de Janeiro: Paz e Terra, 1988.

FAYE, E. et. ali. Heidegger, le sol, la communauté, la race. Dir. Emmanuel Faye. Paris: Beauchesne, 2014.

HEIDEGGER, M. Contribuições à filosofia. Do acon- tecimento-apropriador. Trad. Marco Antonio Casanova. Rio de Janeiro: Via Verita, 2015. . Meditação. Trad. Marco Antonio Casanova. Rio de Janeiro: Vozes, 2010. Schwarze Hefte. Überlegungen II-VI. Ed. Peter Trawny. Frankfurt: Klostermann, 2014. . Schwarze Hefte. Überlegungen VII-XI. Ed. Peter Trawny. Frankfurt: Klostermann, 2014. 

. Schwarze Hefte. Überlegungen XII-XV. Ed.

Peter Trawny. Frankfurt: Klostermann, 2014.

IHDE, D. Heidegger's Technologies. Phenomenological Perspectives. New York: Fordham U. Press, 2010.

VIETTA, S. Etwas rast um den Erdball...Martin Heidegger: Ambivalente Existenz und Globalisierungskritik. Wilhelm Fink Verlag, 2015.

NANCY, J-L. Banalité de Heidegger. Paris: Galilée, 2015.

SCHUBACK, M.C.S. Heidegger, die Juden, Heute. In: Heidegger und die Juden, noch ein mal. Ed. Andrew Mitchell, Peter Trawny. Frankfurt: Klostermann, 2015.

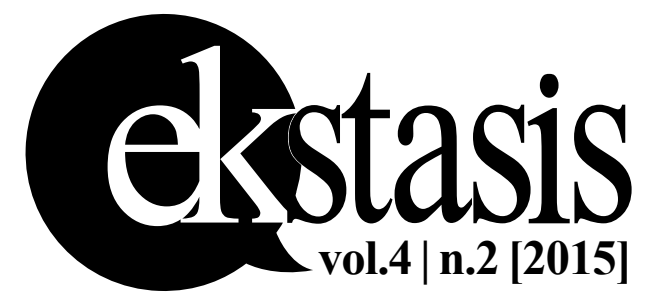

